Bond University

Research Repository

\title{
To forgive or retaliate? How regulatory fit affects emotional reactions and repurchase decisions following product failures
}

Atav, Gizem; Chatterjee, Subimal; Roy, Rajat

Published in:

Journal of Consumer Marketing

DOI:

10.1108/JCM-05-2020-3843

Licence:

CC BY-NC

Link to output in Bond University research repository.

Recommended citation(APA):

Atav, G., Chatterjee, S., \& Roy, R. (2021). To forgive or retaliate? How regulatory fit affects emotional reactions and repurchase decisions following product failures. Journal of Consumer Marketing, 38(4), 397-409. https://doi.org/10.1108/JCM-05-2020-3843

\section{General rights}

Copyright and moral rights for the publications made accessible in the public portal are retained by the authors and/or other copyright owners and it is a condition of accessing publications that users recognise and abide by the legal requirements associated with these rights.

For more information, or if you believe that this document breaches copyright, please contact the Bond University research repository coordinator 
To Disengage or to Reengage? How Regulatory Fit Affects Emotional Reactions and Product Engagement Following Product Failures

Abstract

Purpose: When a product fails out of negligence on the seller's part, consumers can either disengage from the brand/seller, more so if encouraged by a third party (e.g., lawyer) to do so, or reengage with the brand/seller should the seller admit responsibility/apologize. In this research, we examine how the fit between the frame of the message sent by the seller/third party (promotion or prevention frame) and the consumer's temporally induced regulatory orientation (promotion/prevention focus) affects such reengagement/disengagement intentions.

Design, methodology, approach: We conduct two between-subjects laboratory experiments. We temporally induce a promotion or prevention orientation in our participants and thereafter ask them to imagine experiencing a product failure and listening to (1) the CEO apologize for the harm (eliciting sympathy/reengagement), or (2) a lawyer invite them to seek damages for the harm (eliciting anger/disengagement). We frame the messages from the $\mathrm{CEO} /$ lawyer such that they either fit with a promotion mindset or a prevention mindset.

Findings: We find that although a frame-focus fit (compared to a frame-focus misfit) engenders reengagement universally across promotion and prevention oriented consumers, the same fit encourages more disengagement among prevention-oriented than promotion-oriented consumers.

Practical implications: Our results suggest that managers can lessen the fallout from product failures by putting consumers in a promotion mindset. Such a mindset not only 
strengthens the effect of a promotion framed apology, it also makes consumers less receptive to messages encouraging that they seek damages or otherwise disengage from the firm.

Originality/value: Our paper is the first to examine the emotional underpinnings of the "feeling right" phenomenon arising from the frame-focus fit between message frame and regulatory orientation. We show that whereas sympathy gives rise to feeling right about forgiving/reengaging with the brand/seller, anger gives rise to feeling right about retaliating/disengaging from the brand/seller

Keywords: Regulatory Fit; Anger; Sympathy; Apology; Product Failure; Paper Type: Research paper 


\section{Introduction}

Product and service failures are common in the marketplace and they often stem from negligence on the seller's part. In the last few years alone, we have seen companies incur significant financial and reputational costs from product failures stemming from their negligence, such as malfunctioning ignition switches (General Motors; Carrns, 2014), sticking accelerator pedals (Toyota; Krolicki and Kim, 2010) and marine oil spills (BP's Deepwater Horizon; Shultz et al., 2015). Once these failures are discovered, the sellers (henceforth referred to as the transgressor) begin their recovery efforts starting usually by apologizing to the affected consumers (henceforth victims) and/or offering compensation for pain and suffering (Tsarenko and Tojib, 2015; Yuan et al., 2016). However, very soon, if not concurrently, the victims are also encouraged to bring legal actions against the transgressor (e.g., a lawyer canvassing victims to join in a class action lawsuit; Schwartz, 2017). Such class action suits can create significant financial costs for the firms. For example, despite the formal apologies offered by the CEOs of Toyota, GM, and BP, the legal costs were more than \$1 billion (Martyn, 2017), \$2 billion (Storace, 2017), and \$20 billion (McLean and Chapple, 2015) for these companies.

Should the victim forgive the transgressor and forget the harm done, or should the victim retaliate against the transgressor for the harm done? Whereas forgiveness means that the victim is willing to reengage with the transgressor (Aquino et al., 2001), retaliation indicates that the victim wishes to disengage from the transgressor (Bechwati and Morrin, 2003; Gregoire et al., 2010). In this research, we investigate these conflicting responses in two laboratory studies. In Study 1, we prime participants to forgive the transgressor by exposing them to an apology from a CEO, and in Study 2 we 
prime them to retaliate against the transgressor by inviting them to join other victims in a class action law suit initiated by a legal firm. We identify the two emotions that drive the victim in one direction or the other, i.e., sympathy in the case of forgiveness/reengagement (Eaten and Struthers, 2006; Laer and Ruyter, 2010) and anger in the case of retaliation/disengagement (Graham et al, 2011; McColl-Kennedy et al., 2009). We find that the fit or misfit between a victim's regulatory focus (promotion/prevention orientation; Higgins 1997, 2000) and the frame of our message (e.g., a promotion/prevention framed apology from the CEO; a promotion/prevention framed invitation to join a class action lawsuit) affects these emotions/intentions in very different ways. When the victims are encouraged to forgive the transgressor, the focusframe fit, compared to the focus-frame misfit, makes the victims more sympathetic/reengaging towards the transgressor, and equally so among promotion and prevention-oriented victims. However, if the victims are encouraged to retaliate against the transgressor, the focus-frame fit, compared to the focus-frame misfit, makes prevention-oriented victims more angry/disengaging compared to promotion-oriented victims.

Our research contributes to both theory and practice. For theory, we expand in three ways past research which suggests that a focus-frame regulatory fit makes the victim feel 'just right' about forgiving the transgressor (Santelli et al., 2009). First, we study focus-frame fit effects not just on forgiving/reengaging intentions but also on retaliating/disengaging intentions. Second, we study the emotions (sympathy and anger) associated with the so-called 'just right' feeling emanating from regulatory fit. Most importantly, and third, we show that the victim's regulatory focus moderates the 
regulatory fit effects in different ways - whereas the fit-induced sympathy/reengaging is equally strong among promotion and prevention oriented victims, the fit-induced anger/disengaging is stronger among prevention oriented victims.

For practice, our results offer firms two potential avenues to minimize the fallout from product failures. First, should the companies wish to seek forgiveness, their apologies should match the predominant regulatory orientation of the culture they operate in (promotion focus in Western cultures and prevention orientation in Eastern cultures). Second, should the companies wish to discourage the victims from retaliation, they should temporally induce a promotion-centric mindset in the victims by stressing how they can benefit by reengaging with the company.

2. Theory

\subsection{Post-Transgression Messages and Emotions They Elicit}

A victim can cope with an offense in two ways - forgiving the transgressor and forgetting the harm done or retaliating against the transgressor for the harm done and seeking damages (Palanski, 2012). Whereas forgiveness implies a process of overcoming resentment and reengaging with the transgressor (behaving as if nothing has happened; Tsarenko and Tojib, 2012), retaliation indicates that the victim wishes to get even by punishing, and disengaging away from the transgressor (Aquino et al, 2001; 2006). For example, the victim may switch to a rival firm (even if the switch proves to be suboptimal, Bechwati and Morrin, 2003), spread negative word of mouth, complain, and/or commit other hostile acts (Gregoire et al, 2010). 
What leads a victim to move in one direction or the other? Research suggests that how the transgressor responds to the transgression may have a big role to play. For example, the victim is likely to forgive and reengage with the transgressor if $\mathrm{s} / \mathrm{he}$ feels that (1) s/he has been heard and understood (Frantz and Bennigson, 2005), and (2) the transgressor has accepted responsibility, appears remorseful (Darby and Schlenker 1989; Scher and Darley 1997), and shows compassion (Moon and Rhee, 2012).

On the other hand, if the transgressor does not take responsibility, then the victim is very likely to retaliate against the transgressor and seek damages. For example, when Equifax offered one year free credit monitoring and identity theft protection for the victims of their data breach, the company initially inserted a clause whereby the victim, first, had to agree to forced arbitration and sign away the rights to her day in court should there be a class action lawsuit against Equifax (Hembree, 2017). However, a furious consumer backlash forced Equifax to back out of this clause and more than thirty lawsuits seeking class-action status was filed within days of the data breach (one lawsuit demanding more than $\$ 70$ billion in damages; Schwartz, 2017). This example is important because it suggests that how a third party responds to the transgression (in this case a law firm filing a class action lawsuit) can move the victim to retaliate against the transgression.

We can split the desire to forgive the transgressor and the desire to retaliate against the transgressor into an emotional dimension and a decisional dimension. In the case of forgiveness, the decisional dimension is to return the relationship to what it was before the transgression (e.g., I will forgive the company for my troubles; I will buy again from the company). This decision, in turn, is driven by an emotional dimension of 
sympathy (Eaten and Struthers, 2006; Worthington et al., 2006; e.g., I feel sorry for the company, I feel sympathy for the company). As the victim feels more sorry/sympathy, the transgressor begins to look more sincere and repentant (deserving of forgiveness) and less malicious and evil (less deserving of punishment; Darby and Schlenker 1982, Eaton and Struthers 2006).

In the case of retaliation, the decisional dimension is to disengage from the transgressor after recognizing that the transgressor is culpable for the mishap (e.g., I will retaliate against the company for the harm done to me; I will never buy again from the company). The emotional dimension of anger (Graham et al, 2011; McColl-Kennedy et al., 2009), in turn, drives this decision (e.g., I feel angry with the company, I feel like punishing the company). For example, research shows that there is a direct and positive relationship between anger and the likelihood to psychologically retaliate against a transgressor in a variety of interpersonal (e.g., friendships, romantic, and work relationships; Eaton and Struthers, 2006) and business contexts (e.g., angry consumers spreading negative word of mouth following service failure by a restaurant; Bonifield and Cole; 2007). Indeed, the relationship between anger and retaliation is so strong (HajSalem and Chebat, 2014) that some authors have suggested that retaliation's main purpose is to relieve anger (Zourrig et al., 2009).

In the next section, we present the central premise of our paper, namely, how we can frame the focal message and intensify these emotions/strengthen the victim's reengagement/disengagement intentions. As we describe below, we operationalize message frame based on how the contents of the message fit or does not fit with the promotion or prevention orientation of the consumers (Higgins, 1997). 
2.2. Regulatory Focus, Fit, and the Feeling Right Mechanism

Regulatory focus theory (Higgins 1997) proposes that a consumer pursues her goals in a way that is consistent with her regulatory orientation or focus. For example, a promotion-focused consumer seeks to attain idealistic goals and is concerned with advancement and accomplishment making him/her sensitive to the presence or absence of positive outcomes. Therefore, s/he prefers to use an eagerness strategy to accomplish her goals (e.g., Mourali, Böckenholt, and Laroche, 2007). On the other hand, a preventionfocused consumer seeks to fulfill his/her duties and responsibilities, and is concerned with safety and protection, making him/her sensitive to the absence or presence of a negative outcome. Therefore, s/he prefers to use a vigilant strategy to accomplish her goals (e.g., Mourali et al., 2007).

According to Higgins (2000), a regulatory fit occurs in two ways. First, as described above, fit occurs when a consumer adopts (or is made to adopt) a goal seeking strategy that is congruent with his/her regulatory orientation. Second and more important to us, fit occurs when the contents of a message matches a consumer's regulatory orientation. For example, when an orange juice offers promotion benefits such as energy and taste, the message frame fits with the regulatory orientation of a promotion-focused consumer but not a prevention focused consumer. However, when the same juice offers prevention benefits such as preventing cardiovascular disease, the message frame fits with the regulatory orientation of a prevention-focused consumer but not a promotionfocused consumer; Aaker and Lee, 2001). 
The occurrence of a frame-focus regulatory fit leads to two important outcomes. First, there is a "feeling right" or process component that make the consumer feel that $\mathrm{s} /$ he is going about her decision in a correct manner. Second, there is a "strength of engagement" or evaluation component that makes the consumer more committed to his/her actions such as greater attachment to the chosen brand (Avnet and Higgins, 2006; Freitas and Higgins, 2002). For example, Santelli et al. (2009) investigated the role of regulatory fit within the domain of interpersonal forgiveness, where a transgressor lets a colleague down on an important presentation and then apologizes for his/her behavior. The authors compared two types of apology. A promotion-framed apology attempting to return the relationship to a positive level (i.e., achieve a gain), and a prevention-framed apology trying to prevent the relationship from deteriorating further (i.e., avoid more loss). The authors found that (1) the victim is more (less) likely to forgive the transgressor when the apology frame fits (misfits) with her regulatory focus and (2) the frame-focus fit work by making the victim feel that forgiving the transgressor is the right thing to do.

We extend the work of Santelli et al. (2009) in several ways. First, we examine a business to consumer context, as opposed to an interpersonal context, where the transgression occurs because of a service/product failure. There is a close resemblance between how consumers related to a brand and how they relate to a person. For example, consumers can feel disappointed or hurt by a brand (Plummer, 1984; Tsarenko and Tojib, 2015), but, just as in the case of interpersonal relationships, they are less likely to end their relationship if they are strongly attached/committed to the brand (Sinha and Lu, 2016). Second, in addition to investigating the role of regulatory fit in a positive domain 
(forgiving/reengaging with the transgressor), we also investigate the role of fit in a negative domain (retaliating/disengaging from the transgressor). Third, as we show next, we expand the role of regulatory fit by arguing that the fit strengthens the ultimate intention to reengage/disengage by enhancing the associated emotion of sympathy/anger.

\subsection{The Role of Regulatory Fit in Enhancing Sympathy or Anger}

The experience of "feeling right" is a non-emotional and non-affective feeling (Cesario et al., 2004). Therefore, when we say that the victim feels right about her actions (forgiving/retaliating against the transgressor), we do not quite know what makes the victim feel right. For example, the victim may feel that it is right to reengage with the transgressor because s/he feels sorry for the consumer (e.g., the transgressor is not at fault and others are treating the transgressor unfairly). Conversely, the victim may feel that it is right to disengage from the transgressor because $\mathrm{s} / \mathrm{he}$ feels angry with the transgressor (e.g., the transgressor is not accepting responsibility and/or blaming others).

Although there may be many reasons why it feels right to reengage with, or disengage from, the transgressor, we focus on the emotions such reasons elicit in the victims. As we have discussed elsewhere, literature suggests that feelings of sympathy drive the decision to forgive and reengage (Eaton and Struthers, 2006). Therefore, it is likely that if the victim feels that it is just right to forgive, and reengage with, the transgressor, s/he also has more sympathy towards the transgressor. Similarly, since anger towards the transgressor drives the decision to retaliate (Graham et al, 2011; McColl-Kennedy et al., 2009), it is likely that if the victim feels that it is just right to 
retaliate against, and disengage from, the transgressor, s/he also feels more angry towards the transgressor.

The above discussions imply two things. First, suppose that a transgression causes harm to the victim, and s/he subsequently comes across a message asking him/her to forgive the transgressor (e.g., an apology from the CEO). The victim will feel more sympathy towards, and be more likely to reengage with, the transgressor if the frame of the apology matches or fits with his/her regulatory focus relative to a situation where there is a misfit or mismatch between the frame and the focus. Conversely, suppose the victim comes across a message encouraging him/her to punish the transgressor (e.g., a lawyer inviting the victim to join a class action suit against the transgressor to seek damages). The victim will feel angrier towards, and be more likely to disengage from, the transgressor if the frame of the message matches or fits with his/her regulatory focus relative to a situation where there is a misfit or mismatch between the frame and the focus.

\subsection{The Moderating Role of Regulatory Focus}

So far, we have argued that a match or fit between a (message) frame and a (regulatory) focus strengthen the emotional reactions to a transgression (sympathy versus anger). The final research question that we address is whether such fit effects will differentially affect promotion and prevention-focused victims. One way to address this issue is to compare the valence of the underlying emotion, that is, if it is a positive or negative emotion (Scherer, 1984) and assess the fit of the emotion with the victim's regulatory orientation. For example, one could argue that sympathy (and the subsequent 
inclination to forgive and reengage with the transgressor) is a positive (approach)

emotion, and, since promotion-oriented consumers are more sensitive to the presence and absence of positives, fit effects inducing sympathy should be stronger among promotion focused consumers. Similarly, anger (and the subsequent inclination to retaliate against the transgressor) is a negative emotion, and, since prevention-oriented consumers are more sensitive to the presence and absence of negatives, it is likely that the fit effects inducing anger will be stronger among prevention-focused consumers.

One caveat, however, is in order. Molden and Finkel (2010) studied offenses in interpersonal relationships and found that both promotion and prevention oriented victims were equally likely to forgive the transgressor, but for different reasons. The promotionoriented victims forgave the transgressor expecting that their trust in their partner will advance or promote their relationship. The prevention-oriented victims forgave their partners expecting that their commitment would prevent their relationship from deteriorating further. The Molden and Finkel (2010) study appears to indicate that fit effects generating sympathy/forgiveness should be equally strong for promotion and prevention-oriented victims. However, since our focus is on a person to brand relationship and not on a person-to-person relationship, whether the same results will hold remains an empirical question.

Based on the above discussions, we formulate the hypotheses for this paper:

H1: A regulatory fit between the frame of message seeking forgiveness and a victim's regulatory focus, relative to a regulatory misfit, will generate greater sympathy for the transgressor, and make the victim more inclined to forgive/reengage with the transgressor. This fit-induced sympathy/forgiveness effect should be stronger among promotion-focused victims relative to prevention-focused victims. (Figure 1A) 
$\mathrm{H} 2$ : A regulatory fit between the frame of message encouraging retaliation and a victim's regulatory focus, relative to a regulatory misfit, will generate more anger towards the transgressor, and make the victim more inclined to retaliate/disengage from the transgressor. This fit-induced anger/retaliation effect should be stronger among prevention-focused victims relative to promotion-focused victims, (Figure 1B)

Insert Figure 1 about here

\section{Study 1}

3.1 Procedure

\subsubsection{Sample and Design}

One hundred and twenty three undergraduate students (69 females) from a large private university participated in a 2 (regulatory focus: promotion and prevention) by 2 (regulatory fit: fit and misfit) between subjects laboratory experiment.

\subsubsection{Stimuli}

We ran Study 1 in two parts. In the first part, we induced (temporal) promotion or prevention orientations across participants using a well-established regulatory focus induction protocol (Cornwell and Higgins, 2016; Freitas and Higgins, 2002; Higgins et. al., 1994). Participants wrote a short personal essay for about five minutes describing their hopes and aspirations (promotion focus) or their duties and obligations (prevention focus) when they were growing up and now.

In the second part, we asked all participants to imagine that a carmaker has recalled the new car that they have purchased because of some technical faults, and they are now watching the $\mathrm{CEO}$ of the car company, on television, apologize to their 
customers. We gave participants either a promotion-framed or a prevention-framed message from the CEO, thereby creating a regulatory fit (promotion focus matched with promotion frame or prevention focus matched with prevention-frame) or regulatory misfit (promotion focus mismatched with prevention frame or prevention focus mismatched with promotion frame; see Table 1). As shown in Table 1, the promotion-framed message used words/phrases like "I hope that our relationship can move forward," "I will gain back your trust," and "I want all customers to regain confidence in the company." The prevention-framed message used words/phrases like "My duty is to repair our relationship," "I am obligated not to lose your trust," and "I want to ensure that our customers not lose confidence in our company."

Insert Table 1 about here

\subsubsection{Measures}

The manipulation checks for regulatory focus included three 7-point items measuring how much participants felt (a) happy (as opposed to sad), (b) relieved (as opposed to anxious) and (c) if what they wanted to do felt more important (as opposed to what they ought to do; $\alpha=0.75$ ). Higher numbers on these items are indicative of a promotion mindset and lower numbers are indicative of a prevention mindset (Keller, 2006).

Two 9-point agree/disagree items measured how sympathetic participants felt towards the transgressor (Ifeel sorry for the company, I feel sympathy for the company; $\alpha$ $=0.81$. Three 9-point agree/disagree items measured their intentions to reengage with the transgressor (I am likely forgive the company for my troubles, I am likely to buy from the company again, I am likely to recommend the company's products to my friends; $\alpha=$ 
0.87). A factor analysis on the three items retained a one-factor solution (eigenvalue $>1$ ) explaining $91 \%$ of the total variance in all three items.

Since some consumers are more forgiving than others are in general (Toussaint and Webb, 2005), we measured trait-forgiveness for each participants with five 5-point, agree/disagree items (e.g., I can forgive others for almost anything, I have always forgiven those who have hurt me; $\alpha=0.74$, Berry et al., 2005). We created a composite trait forgiveness score for each participant and treated it as a control variable in our analyses.

\subsection{Analysis and Results}

\subsubsection{Manipulation checks}

Manipulation checks for regulatory focus showed that how participants felt (relieved, happy, and focused on what they wanted to do) varied in the intended directions and did not interact with the fit manipulations. The composite measure of the three feelings items was significantly higher in the promotion condition relative to the prevention condition ( $M$ 's of 5.31 and 4.09, $F(1,119)=48.13, p<0.001)$ and this pattern was unchanged across the regulatory fit and misfit conditions (interaction $F(1,119)<1$ ).

\subsubsection{Cell Means and ANOVA}

Table 2 shows the means for the key measures (feelings of sympathy and intentions to reengage with the transgressor) across the four combinations of regulatory focus and fit conditions.

Insert Table 2 about here 
We conducted ANOVAs on sympathy and reengagement intentions, with regulatory focus (promotion, prevention) and regulatory fit (fit, misfit) and their intention as predictors, and trait forgiveness and gender as control variables. In addition to the participant's trait forgiveness score, we also control for gender given that that women are, in general, more forgiving than men (Miller, Worthington and Daniel, 2008).

As predicted in $\mathrm{H} 1$, relative to a frame-focus misfit, a frame-focus fit significantly increased sympathy towards the transgressor ( $M$ 's of 4.63 and $3.62 ; F(1,117)=9.58, p<$ $.01)$. However, and contrary to $\mathrm{H} 1$, the fit effect was not qualified by regulatory focus $(F(1,117)<1)$. Similarly, relative to a frame-focus misfit, a frame-focus fit significantly increased reengagement intentions ( $M$ 's of 5.01 and $2.98 ; F(1,117)=58.22, p<.0001$ ), but it was not qualified by regulatory focus $(F(1,117)<1$; see Table 2 for the means across the conditions).

\subsubsection{Process Tests}

Figure 1A implicates a moderated mediation model, with regulatory focus moderating the indirect effect of sympathy linking regulatory fit with reengagement intentions. However, since the ANOVAs did not show a significant interaction of regulatory focus and fit on the mediator (sympathy) and the outcome (reengagement intentions), we tested for a simple mediation model aggregated across promotion and prevention participants, where regulatory fit affects reengagement intentions by generating more sympathy for the transgressor (Hayes, 2018; see Table 3).

Insert Table 3 Here 
As shown in Table 3's top panel, regulatory fit increases sympathy for the transgressor $(\beta=0.97, t=3.11, p<0.01)$ showing the predictor to mediator link. The middle panel shows that sympathy increases the inclination to reengage with the transgressor after we have factored into consideration the effects of regulatory fit ( $\beta=$ $0.25, t=3.48, p<.001)$ showing the mediator to outcome link. Finally, as shown in the bottom panel, the indirect effect of regulatory fit $(0.97 \times 0.25$; fit affecting reengagement intentions by enhancing sympathy for the transgressor) is significant (the $95 \%$ bootstrapped confidence interval for the fit effects does not straddle zero).

\subsection{Discussion}

In Study 1, we show that how framing an apology that fits a victim's regulatory orientation (e.g., a promotion-framed apology targeted to a promotion-oriented victim/a prevention-framed apology directed to a prevention-oriented victim) can increase sympathy and make the victim more inclined to reengage with the transgressor. However, such fits effects are equally strong for promotion and prevention oriented victims suggesting that sympathy for the transgressor may be a more universal trait cutting across promotion and prevention orientations than, say, anger, which we study next.

\section{Study 2}

\subsection{Procedure}

\subsubsection{Sample and Design}


One hundred and twenty three undergraduate students (57 females) from a large university participated in a 2 (regulatory focus: promotion and prevention) by 2 (regulatory fit: fit and misfit) between subjects laboratory experiment. All Study 2 participants were new to the study (that is they did not participate in Study 1).

\subsubsection{Stimuli}

Like Study 1, we ran Study 2 in two parts. In the first part, we induced (temporal) promotion or prevention orientations across participants following the same protocols used in Study 1. In the second part, we asked all participants to imagine that a carmaker has recalled the new car that they have purchased because of some technical faults, and they are watching a lawyer, on television, asking all affected consumers to join a class action lawsuit against the car company. We gave participants either a promotion-framed or a prevention-framed message from the lawyer thereby creating a regulatory fit or misfit between the victim and the message (see Study 1). As shown in Table 4, the promotion-framed message used words/phrases like "the company could have ensured things went right," "the company did not strive to do everything possible," and "the company could have continued to enjoy your trust." The prevention-framed message used words/phrases like "the company could have prevented things from going wrong," "the company did not fulfil their obligations and failed to do everything possible," and "the company could have avoided losing your trust."

Insert Table 4 about here

\subsubsection{Measures}

The three manipulation check items for regulatory focus were the same as in Study 1 (relieved, happy, and focused on what they wanted to do; $\alpha=0.68$ ). The 
composite of two 9-point agree/disagree item measured how angry participants felt towards the transgressor (I feel very angry with the company, I feel like punishing the company; $\alpha=0.93)$.

A composite of three 9-point agree/disagree items measured how inclined participants were to disengage with the transgressor (I am likely to retaliate against the company for my troubles, I am likely not to buy from this company again, I am likely not to recommend this company's products to my friends; $\alpha=0.74$ ). A factor analysis on the three items retained a one-factor solution (eigenvalue $>1$ ) explaining $88 \%$ of the total variance in all three items.

Finally, five 5-point, agree/disagree items measured how vengeful the participants were in general (trait vengeance; e.g., I hold a grudge too long, If someone treats me badly I treat him/her the same, $\alpha=0.55$; Berry et al., 2005). As in Study 1, we created a composite trait vengeance score for each participant to control for consumer heterogeneity in the inclination to retaliate.

\subsection{Analysis and Results}

\subsubsection{Manipulation checks}

As in Study 1, the composite manipulation check measure for regulatory focus varied in the intended directions and did not interact with the fit manipulations ( $M$ 's of 4.97 and 4.10 for promotion and prevention conditions, $F(1,119)=30.55, p<0.001)$.

\subsubsection{Cell Means and ANOVAs}


Table 5 shows the means for the key measures (anger, and intentions to disengage form the transgressor) across the four combinations of regulatory focus and fit conditions.

Insert Table 5 about here

We conducted ANOVAs on anger and disengagement intentions, with regulatory focus (promotion, prevention) and regulatory fit (fit, misfit) and their intention as predictors, and trait vengeance and gender as control variables. In addition to trait vengeance, we select gender as a control given past research showing that men, in general, are more accepting of retaliation or revenge, compared to women (CotaMcKinley, Woody and Bell, 2001).

As predicted in $\mathrm{H} 2$, relative to a frame-focus misfit, a frame-focus fit significantly increased anger with the transgressor ( $M$ 's of 6.20 and $5.38 ; F(1,117)=6.59, p=.01)$ and the main effects was qualified by regulatory focus $(F(1,117)=5.60, p=.02)$. Among prevention-focused participants, the frame-focus fit significantly increased anger with the transgressor $(M$ 's of 6.79 and $5.22 ; F(1,57)=12.12, p<.001)$ but not among the promotion-focused participants ( $M$ 's of 5.61 and $5.48 ; F(1,58)<1)$.

Similarly, relative to a frame-focus misfit, a frame-focus fit significantly increased reengagement intentions $(M$ 's of 7.35 and $5.49 ; F(1,117)=68.00, p<.0001)$ and the main effect was qualified by regulatory focus that approached statistical significance $(F(1,117)=3.72, p=.06)$. Among prevention-focused participants, the frame-focus fit significantly increased intentions to reengage with the transgressor ( $M$ 's of 7.69 and $5.39 ; F(1,57)=40.64, p<.0001)$ but slightly less among the promotionfocused participants ( $M$ 's of 7.00 and $5.89 ; F(1,58)=24.72, p<.001$ ). 


\subsubsection{Process Tests}

Table 6 shows the process tests results testing Figure 1B (a moderated mediation model; Hayes 2018).

Insert Table 6 about here

As shown in Table 6, regulatory fit affects the mediator (feelings of anger), which in turn affects the outcome (disengagement intentions), but these effects are conditional on regulatory focus (promotion or prevention). Consistent with $\mathrm{H} 2$, the top panel shows that regulatory fit does not enhance anger towards the transgressor conditional on a promotion orientation (Focus $=0 ; \beta=0.06, t<1$ ) but transitioning to a prevention orientation significantly increase that anger (the Fit by Focus interaction is significant; $\beta$ $=1.31, t=2.37, p=0.02)$. The middle panel shows that anger increases intentions to disengage from the transgressor $(\beta=0.23, t=3.36, p=0.001)$ after we have controlled for any direct fit effect on disengagement intentions. Finally, as shown in the bottom panel, the indirect effect of regulatory fit (fit affecting disengagement intentions by enhancing anger towards the transgressor) is significant among the prevention-focused participants (the $95 \%$ bootstrapped confidence interval for the fit effects does not straddle zero) but not among the promotion-focused participants (the $95 \%$ bootstrapped confidence interval for the fit effects straddles zero).

\subsection{Discussions}

In Study 2 we study how exposing victims of a transgression to a message of culpability (e.g., a class action lawsuit claiming that the transgressor is at fault) affects their reactions. We find that prevention-oriented victims get angrier towards the 
transgressor if the frame of the message matches their regulatory focus (relative to when it does not), which, in turn, increases their intention to retaliate against/disengage from the transgressor. On the other hand, the message fit (or misfit) does not affect the anger/retaliation intentions of promotion-oriented victims. Therefore, and unlike Study 1 (which studies fit effects in the domain of forgiveness), the fit effects in the domain of retaliation are qualified by the victim's regulatory focus.

\section{General Discussion}

Our paper's main objective is to investigate how regulatory fit between a consumer's regulatory focus and a message of contrition from a transgressor (or a message holding the transgressor culpable) affects his/her intentions to forgive the transgressor (retaliate against the transgressor). We make three main contributions. First, whereas past work has shown that regulatory fit between a message of contrition (transgressor's apology) and the victim's regulatory focus increases forgiveness in interpersonal relationships (Santelli et al., 2009), we show that the same effects play out in a consumer to business context following a service/product failure and a subsequent message of contrition from the CEO (Study 1).

Second, we extend research from the domain of forgiveness to the domain of retaliation (where the victim is exposed to a message asking her to retaliate against the transgressor who is responsible for the product failure). Here, we show that regulatory fit between a message of culpability and the victim's regulatory focus increases retaliatory intentions, but only among prevention-oriented consumers. This finding has two important implications. First, while ample research has shown the effect of regulatory fit 
in enhancing positive responses, we show that regulatory fit can be just as effective in enhancing negative responses (Avnet and Higgins, 2006). Second, we show that while sympathy/forgiveness is a universal behavior (same across promotion and prevention victims), anger/retaliation is stronger among (or more specific to) prevention-focused victims.

Finally, and third, we extend research on the "feeling right" mechanism thought to underlying fit effects on forgiveness intentions (Santelli et al., 2009). While feeling right is indeed a primary component of regulatory fit effects, it is a neutral emotion, meaning that some other emotions strengthens this just-right feeling. We examine what makes these intentions (forgiveness or retaliation) feel right. In Study 1 (2), we find that regulatory fit increases consumer sympathy (anger), resulting in greater forgiveness (retaliation) intentions.

\subsection{Managerial Implications}

Our findings carry several implications for practice. First, companies, seeking to recover from a service/product failure, can use these results to match their messages of contrition to the regulatory orientation of the country or culture they are reaching out to. While individual differences still reside within a country, Eastern and collectivistic cultures (e.g. China) are more prevention-oriented, while Western and individualistic cultures (e.g. USA) are more promotion-oriented (Higgins, 2008).

Second, recovery attempts usually begin with an apology from the CEO, and while managing these messages are important, the companies should be aware that the victims are exposed to counter messages as well (holding the company culpable for the 
failure). Here, our results suggest that inducing a promotion mindset (Cesario et al., 2004) may help in keeping the consumer backlash and anger in check. Indeed, one of the first things that Equifax did following their data breach is offer one year free credit monitoring and identity theft protection. This is important since this was a case where the victims did not know whether their own information had been compromised and Equifax's response mixed a promotion offer (free credit monitoring) and a prevention offer (theft protection).

\subsection{Limitations and Future Research}

There are a few limitations in this paper that offer opportunities for future research. First, whereas our laboratory experiments allow us to achieve high internal validity, they might limit the external validity of our results. Future research may use a field experiment or surveys to replicate our results.

Second, our research looks at the role of regulatory fit in enhancing motivation to forgive or retaliate in two separate studies. Given that victims are often exposed to both types of messages simultaneously, future research might create a scenario where they are exposed to both messages at the same time, and test for their effects.

Third, our research treats regulatory focus as an individual-level moderator and found that prevention-focused victims, relative to promotion-focused victims, are more inclined to retaliate against the transgressor. However, regulatory focus is closely related to other variables such as construal levels (i.e. abstract versus concrete) and mindsets (e.g. fixed versus growth mindsets). Future research might explore the role of these other potential moderators to expand on our findings. 
Fourth, given the effect of culture on consumer willingness to engage in forgiveness and revenge (Zourrig et al., 2015), future research can explore the role of country-of-origin on the relationships explored in this research. For example, in this research, we focused on the role of anger since it is one of the most common emotions experienced in crisis (Lerner and Keltner, 2001; Lerner et al., 2003; Ran et al., 2016) and a precedent of retaliatory behavior. However, the emotions that lead to retaliation might be different in different cultures. For example, whereas undergraduate students from the United States experienced stronger levels of anger before deciding to retaliate (Folkes, 1984), shame mattered more for their Korean counterparts (Shteynberg, 2005) suggesting that expressions of anger is a culturally inappropriate form of self-expression in some cultures (Zourrig et al., 2009). Thus, how shame, in addition to sympathy and anger, can affect the consumer's intention to forgive or retaliate against a transgressor is a fruitful topic for future research. 


\section{References}

Aaker, J. L. \& Lee, A. Y. (2001). "I" seek pleasures and "we" avoid pains: The role of self-regulatory goals in information processing and persuasion. Journal of Consumer Research, 28(1), 33-49.

Aquino, K., Tripp, M. T., \& Bies, J. R. (2001). How employees respond to personal offense: the effects of blame attribution, victim status, and offender status on revenge and reconciliation in the workplace. Journal of Applied Psychology, 86(1), 52-59.

Aquino, K., Tripp, M. T., \& Bies, J. R. (2006). Getting even or moving on? Power, procedural justice, and types of offense as predictors of revenge, forgiveness, reconciliation, and avoidance in organizations. Journal of Applied Psychology, 91(3), 653-68.

Avnet, T., \& Higgins, E.T. (2006). How regulatory fit affects value in consumer choices and opinions. Journal of Marketing Research, 43(1), 1-10.

Bechwati, N. N., \& Morrin, M. (2003). Outraged consumers: Getting even at the expense of getting a good deal. Journal of Consumer Psychology, 13(4), 440-453.

Berry, J.W., Worthington, E. L., O'Connor, L. E., Parrott, L., \& Wade, N. G. (2005). Forgivingness, vengeful rumination, and affective traits. Journal of Personality, 73(1), 183-226.

Bonifield, C., \& Cole, C. (2007). Affective responses to service failure: Anger, regret, and retaliatory versus conciliatory responses. Marketing Letters, 18(1-2), 85-99.

Carrns, Ann (2014). Understanding Particulars of G.M.'s Safety Recall. Retrieved from https://www.nytimes.com/2014/04/05/yourmoney/understanding-gms-safetyrecall.html

Cesario, J., Grant, H., \& Higgins, E. T. (2004). Regulatory fit and persuasion: Transfer from" feeling right." Journal of Personality and Social Psychology, 86(3), 388404.

Cornwell, J. F. M., \& Higgins, E. T. (2016). Eager feelings and vigilant reasons: Regulatory focus differences in judging moral wrongs. Journal of Experimental Psychology: General, 145(3), 338-355.

Cota-McKinley, A., Woody, W. D. \& Bell, P. A. (2001) Vengeance: Effects of Gender, Age and Religious Background. Aggressive Behavior, 27(5), 343-350.

Darby, B. W., \& Schlenker, R. B. (1982). Children's reactions to apologies. Journal of Personality and Social Psychology, 43 (4), 742-753.

Darby, B. W., \& Schlenker, R. B. (1989). Children's reactions to transgressions: Effects of the actor's apology, reputation and remorse. British Journal of Social Psychology, 28(4), 353-364.

Eaton, J., \& Struthers, C. W. (2006). The reduction of psychological aggression across varied interpersonal contexts through repentance and forgiveness. Aggressive Behavior, 32(3), 195-206.

Folkes, S. V. (1984). Consumer reactions to product failure: An attributional approach." Journal of Consumer Research, 10(4), 398-409.

Frantz, M. C., \& Bennigson, C. (2005). Better late than early: The influence of timing on apology effectiveness. Journal of Experimental Social Psychology, 41(2), 201207. 
Freitas, A. L., \& Higgins, E. T (2002). Enjoying goal-directed action: The role of regulatory fit. Psychological Science, 13(1), 1-6.

Graham, J., Nosek, A. B., Haidt, J., Iyer, R., Koleva, S., \& Ditto, H. P. (2011). Mapping the moral domain. Journal of Personality and Social Psychology, 101(2), 366385.

Grégoire, Y., Laufer, D., \& Tripp, M. T. (2010). A comprehensive model of customer direct and indirect revenge: understanding the effects of perceived greed and customer power. Journal of the Academy of Marketing Science, 38(6), 738-758.

Haj-Salem, N., \& Chebat, J. C. (2014). The double-edged sword: The positive and negative effects of switching costs on customer exit and revenge. Journal of Business Research, 67(6), 1106-1113.

Hayes, A. F. (2018). Introduction to Mediation, Moderation, and Conditional Process Analysis. A Regression-Based Approach, Second Edition. New York: Guilford Press.

Higgins, E. T., Roney, JR, C., Crowe, E., \& Hymes, C. (1994). Ideal versus ought predilections for approach and avoidance distinct self-regulatory systems. Journal of Personality and Social Psychology, 66(2), 276-86.

Higgins, E. T. (1997). Beyond pleasure and pain. American Psychologist, 52(12), $1280-$ 1300.

Higgins, E. T. (2000). Making a good decision: value from fit. American Psychologist, 55(11), 1217-30.

Higgins, E. T. (2008). Culture and personality: Variability across universal motives as the missing link. Social and Personality Psychology Compass, 2, 608-634.

Hembree, D. (2017). Consumer Backlash Spurs Equifax to Drop 'Rip-off Clause' In Offer to Security Hack Victims. Retrieved from

https://www.forbes.com/sites/dianahembree/2017/09/09/consumer-anger-overequifaxs-ripoff-clause-in-offer-to-security-hack-victims-spurs-policychange/\#5bd68a0a6e7e

Keller, P. A. (2006). Regulatory focus and efficacy of health messages. Journal of Consumer Research, 33(1), 109-114.

Laer, V. T., \& Ruyter, K. D. (2010). In stories we trust: How narrative apologies provide cover for competitive vulnerability after integrity-violating blog posts. International Journal of Research in Marketing, 27(2), 164-174.

Lerner, S. J., \& Keltner, D. (2001). Fear, anger, and risk. Journal of Personality and Social Psychology, 81 (1), 146-159.

Lerner, S. J., Gonzalez, M. R., Small, A. D., \& Fischhoff. B. (2003). Effects of fear and anger on perceived risks of terrorism: A national field experiment. Psychological Science 14(2), 144-150.

Martyn, A. (2017). Toyota is Liable for a Fatal Car Crash that Sent a Driver to Prison, Appeal Court Rules. Retrieved from https://www.consumeraffairs.com/news/toyota-is-liable-for-a-fatal-car-crash-thatsent-a-driver-to-prison-appeals-court-rules-061517.html

McColl-Kennedy, J. R., Patterson, P. G., Smith, A. K., Brady, M. K. (2009). Customer Rage Episodes: Emotions, Expressions and Behaviors. Journal of Retailing, 85(2), 222-237. 
McLean, R., \& Chapple, I. (2015). BP Settles Final Gulf Oil Spill Claims for \$20 Billion. Retrieved from http://money.cnn.com/2015/10/06/news/companies/deepwaterhorizon-bp-settlement/index.html

Miller, A. J., Worthington, E. L. \& McDaniel, M. A. (2008). Gender and Forgiveness: A Meta-Analytic Review and Research Agenda. Journal of Social and Clinical Psychology, 27(8), 843-876.

Molden, C. D., \& Finkel, J. E. (2010). Motivations for promotion and prevention and the role of trust and commitment in interpersonal forgiveness. Journal of Experimental Social Psychology, 46(2), 255-268

Mourali, M., Böckenholt, U., \& Laroche. M. (2007). Compromise and attraction effects under prevention and promotion motivations. Journal of Consumer Research, 34(2), 234-247.

Palanski, E. M. (2012). Forgiveness and reconciliation in the workplace: A multi-level perspective and research agenda. Journal of Business Ethics, 109(3), 275-287.

Ran, Y., Wei, H., \& Li, Q. (2016). Forgiveness from Emotion Fit: Emotional Frame, Consumer Emotion, and Feeling-Right in Consumer Decision to Forgive. Frontiers in Psychology, 7:1775, doi: 10.3389/fpsyg.2016.01775.

Santelli, G. A., Struthers, C. W., \& Eaton, J. (2009). Fit to forgive: Exploring the interaction between regulatory focus, repentance, and forgiveness. Journal of Personality and Social Psychology, 96(2), 381-94.

Scherer, K. R. (1984). "On the nature and function of emotion: a component process approach," in Approaches to Emotion, eds K. R. Scherer and P. Ekman (Hillsdale, NJ: Lawrence Erlbaum Associates, Inc.), 293-317.

Schwartz, J. M. (2017). Equifax Faces Mounting Anger, \$70 Billion Lawsuit. Retrieved from https://www.bankinfosecurity.com/equifax-faces-mounting-anger-70billion-lawsuit-a-10282

Shteynberg, G. (2005). The Cultural Psychology of Revenge in the United States and South Korea. Thesis Dissertation. University of Maryland, College Park.

Shultz, M. J, Walsh, L., Garfin, D. R., Wilson, F. E., \& Neria, Y. (2015). The 2010 Deepwater Horizon Oil Spill: The Trauma Signature of an Ecological Disaster. The Journal of Behavioral Health Services \& Research, 42 (January), 58-76.

Sinha, J., \& Lu, F. C. (2016). "I" value justice, but "we” value relationships: Selfconstrual effects on post-transgression consumer forgiveness. Journal of Consumer Psychology, 26(2), 265-274.

Storace, R. (2017). GM Looks to Consolidate another Lawsuit over its Faulty Ignition Switches. Retrieved from https://www.law.com/ctlawtribune/sites/ctlawtribune/2017/09/26/gm-looks-toconsolidate-another-lawsuit-over-its-faulty-ignition-switches2/?slreturn=20180110183934

Toussaint, L., \& Webb, J. R. (2005). Theoretical and empirical connections between forgiveness, mental health, and well-being. Handbook of forgiveness, 349-362.

Tsarenko, Y., \& Tojib, D. (2012). The role of personality characteristics and service failure severity in consumer forgiveness and service outcomes. Journal of Marketing Management, 28(9), 1217-1239. 
Tsarenko, Y., \& Tojib, D. (2015). Consumers' forgiveness after brand transgression: the effect of the firm's corporate social responsibility and response. Journal of Marketing Management, 31(17-1), 1851-1877.

Worthington, Jr, L. E., Scherer, M., \& Cooke, L. K. (2006). Forgiveness in the treatment of persons with alcohol problems. Alcoholism Treatment Quarterly, 24 (1/2), 125145.

Yuan, D., Cui, G., \& Lai, L. (2016). Sorry seems to be the hardest word: Consumer reactions to self-attributions by firms apologizing for a brand crisis. Journal of Consumer Marketing, 33(4), 281-291. https://doi.org/10.1108/JCM-02-20151306

Zourrig, H., Chebat, J. C., \& Toffoli, R. (2009). Consumer revenge behavior: a crosscultural perspective. Journal of Business Research, 62(10), 995-1001.

Zourrig, H., Chebat, J. C., \& Toffoli, R. (2015). “In-group love and out-group hate?” A cross-cultural study on customers' revenge, avoidance and forgiveness behaviors. Journal of Business Research, 68(3), 487-499. 


\section{Figure 1}

Process Models

Figure 1A: Study 1

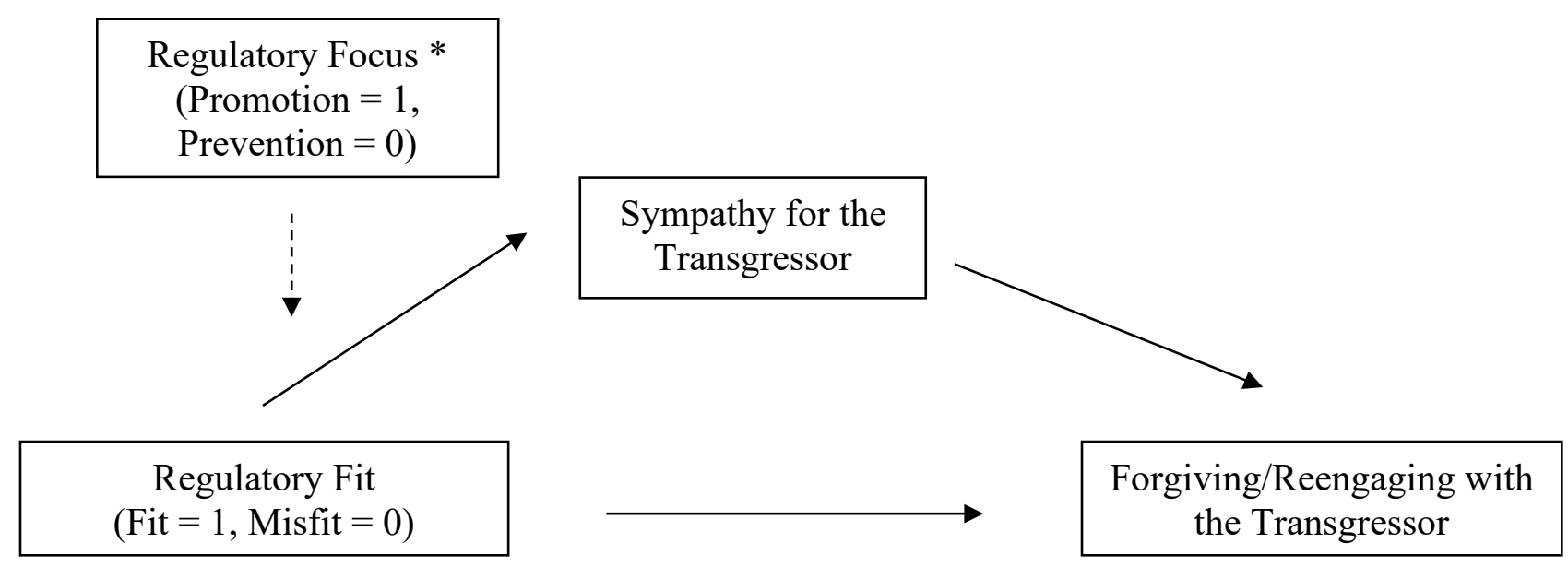

Figure 1B: Study 2

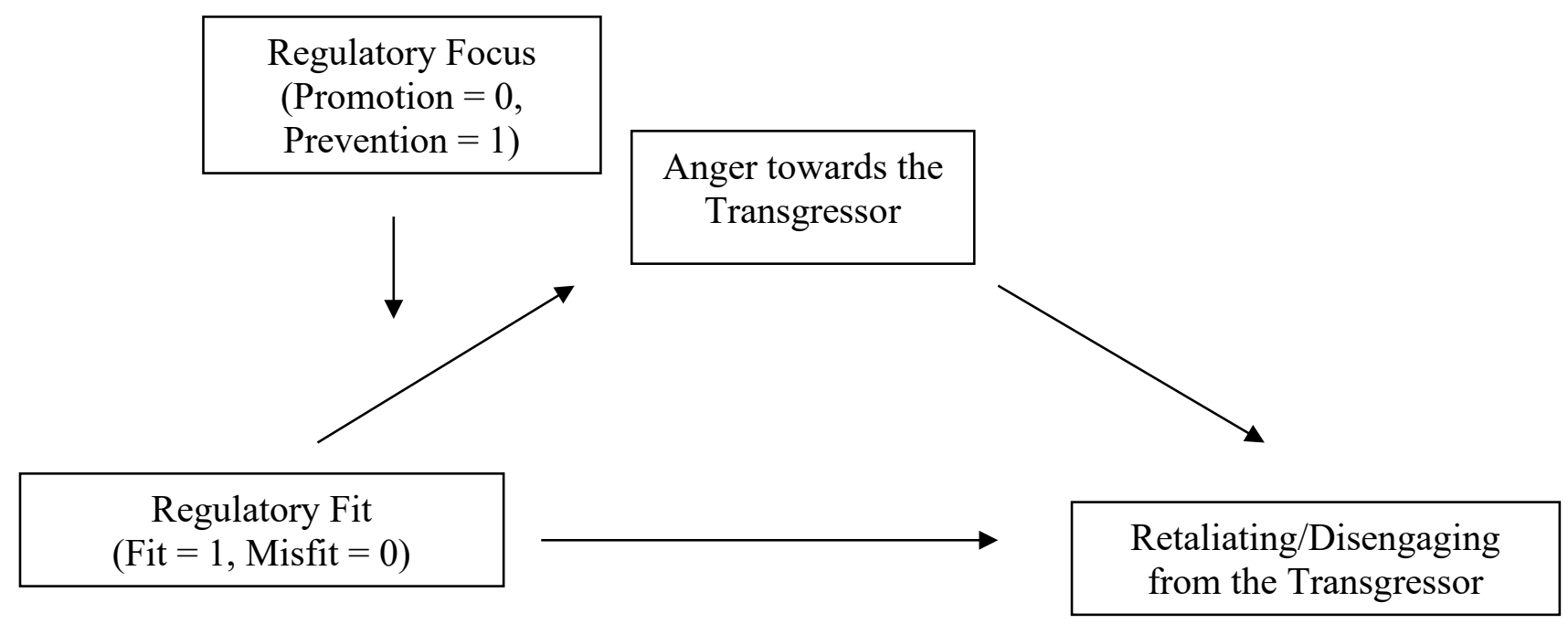

* Dashed line indicates non-significant path in Study 1 


\section{Table 1}

Study 1: Stimuli

\section{Cover Story}

You have purchased a new car from a reputed manufacturer. During your morning commute to work one day, your car breaks down. You cannot start the car and have to call a tow-truck. As a result, you have to miss a very important meeting and cancel all appointments for the day.

It is evening now. You are watching television and the news anchor reports that the problem you experienced with your car is not isolated to your model and the carmaker has recalled several other models for the same problem. The news anchor is interviewing the CEO of the company who is apologizing to the customers. You listen to the CEO say:

\section{Frame Manipulations}

Promotion Frame: I am so sorry and I have to apologize for what has happened to our customers. I hope that our relationship with our customers can move forward after this. I want all our customers to know that I will strive to do whatever it takes to gain back your trust. I want all our customers to regain their confidence in our company.

Prevention Frame: I am so sorry and I have to apologize for what has happened to our customers. My duty is to repair our relationship with our customers. I want all our customers to know that I am obligated to do whatever it takes not to lose your trust. I want to ensure that our customers do not lose their confidence in our company. 
Table 2

Study 1: Cell means and standard deviations

\begin{tabular}{lllllll} 
& & & & \multicolumn{2}{c}{$\begin{array}{c}\text { Intention } \\
\text { to Reengage }\end{array}$} & \multicolumn{2}{c}{$\begin{array}{c}\text { Feelings of } \\
\text { Sympathy }\end{array}$} \\
\cline { 4 - 7 } Regulatory Focus & Fit & $\mathrm{N}$ & Mean & Std. Dev & Mean & Std. Dev \\
\cline { 4 - 6 } Prevention & Fit & 32 & 4.94 & 1.54 & 4.64 & 1.60 \\
Prevention & Misfit & 31 & 2.79 & 1.16 & 3.45 & 1.61 \\
Promotion & Fit & 30 & 5.10 & 1.59 & 4.62 & 1.82 \\
Promotion & Misfit & 30 & 3.17 & 1.43 & 3.80 & 1.83 \\
\hline
\end{tabular}




\section{Table 3}

Study 1: Process tests

A. Dependent Variable: Sympathy

\begin{tabular}{lcccccc} 
& Coefficient & $\begin{array}{c}\text { Standard } \\
\text { Error }\end{array}$ & $\mathrm{t}$ & $\mathrm{p}$ & LLCI & ULCI \\
\hline Constant & 3.1427 & 0.6750 & 4.6556 & 0.0000 & 1.8060 & 4.4793 \\
Fit $($ Fit = 1, Misfit =0) & 0.9725 & 0.3126 & 3.1114 & 0.0023 & 0.3536 & 1.5915 \\
Trait forgiveness & 0.1517 & 0.1950 & 0.7781 & 0.4381 & -0.2344 & 0.5378 \\
Gender (Male $=1$, Female $=0)$ & 0.0038 & 0.3098 & 0.0121 & 0.9903 & -0.6097 & 0.6172 \\
\hline
\end{tabular}

B. Dependent Variable: Intention to Reengage with Transgressor

\begin{tabular}{|c|c|c|c|c|c|c|}
\hline & Coefficient & $\begin{array}{c}\text { Standard } \\
\text { Error }\end{array}$ & $\mathrm{t}$ & $\mathrm{p}$ & LLCI & ULCI \\
\hline Constant & 2.2867 & 0.5770 & 3.9633 & 0.0001 & 1.1441 & 3.4292 \\
\hline Fit $($ Fit $=1$, Misfit $=0)$ & 1.5772 & 0.2555 & 6.1724 & 0.0000 & 1.0712 & 2.0832 \\
\hline Sympathy & 0.2508 & 0.0721 & 3.4806 & 0.0007 & 0.1081 & 0.3935 \\
\hline Trait forgiveness & 0.0487 & 0.1537 & 0.3172 & 0.7517 & -0.2556 & 0.3530 \\
\hline Gender $($ Male $=1$, Female $=0)$ & -0.1481 & 0.2436 & -0.6081 & 0.5443 & -0.6304 & 0.3342 \\
\hline
\end{tabular}

C. Indirect Effect of Fit on Intention to Reengage with Transgressor

\begin{tabular}{lcccc} 
Mediator & Effect & Boot SE & Boot LLCI & Boot ULCI \\
\hline Sympathy & 0.2439 & 0.1079 & 0.0623 & 0.4819 \\
\hline
\end{tabular}

This author accepted manuscript is deposited under a Creative Commons Attribution Non-commercial 4.0 International (CC BY-NC) licence. This means that anyone may distribute, adapt, and build upon the work for non-commercial purposes, subject to full attribution. If you wish to use this manuscript for commercial purposes, please contact permissions@emerald.com. 


\section{Table 4}

Study 2: Stimuli

\section{Cover Story}

You have purchased a new car from a reputed manufacturer. During your morning commute to work one day, your car breaks down. You cannot start the car and have to call a tow-truck. As a result, you have to miss a very important meeting and cancel all appointments for the day.

It is evening now. You are watching television and the news anchor reports that the problem you experienced with your car is not isolated to your model and the carmaker has recalled several other models for the same problem. The news anchor is interviewing a lawyer who is filing a class action suit against the company. You listen to the lawyer say:

\section{Frame Manipulations}

Promotion Frame: The company did not adequately test the components before the car went into production. The company could have ensured that everything went right and continued to enjoy the consumer's trust and confidence. Speaking on behalf of all affected persons, I am sad to note that the company did not strive to do everything possible so that this did not happen. Now the company must answer to, and compensate, consumers like you who have suffered from their negligence.

Prevention Frame: The company did not adequately test the components before the car went into production. The company could have prevented things from going wrong and avoided losing the consumer's trust and confidence. Speaking on behalf of all affected persons, I am sad to note that the company did not fulfil their obligations and failed to do everything possible to prevent this from happening. Now the company can no longer avoid answering to, and avoid compensating, consumers like you who have suffered from their negligence. 
Table 5

Study 2: Cell means and standard deviations

\begin{tabular}{lllcccc} 
& & & \multicolumn{2}{c}{$\begin{array}{c}\text { Intention to } \\
\text { Disengage }\end{array}$} & \multicolumn{2}{c}{$\begin{array}{c}\text { Feelings of } \\
\text { Anger }\end{array}$} \\
\cline { 4 - 6 } Regulatory Focus & Fit & $\mathrm{N}$ & Mean & Std. Dev & Mean & Std. Dev \\
\cline { 4 - 6 } & & & & & & \\
Prevention & Fit & 31 & 7.69 & 0.75 & 6.79 & 1.39 \\
Prevention & Misfit & 30 & 5.39 & 1.72 & 5.22 & 1.60 \\
Promotion & Fit & 31 & 7.00 & 1.24 & 5.61 & 1.85 \\
Promotion & Misfit & 31 & 5.59 & 1.06 & 5.55 & 1.45 \\
\hline
\end{tabular}




\section{Table 6}

Study 1: Process tests

A. Dependent Variable: Anger

\begin{tabular}{lcccccc} 
& Coefficient & $\begin{array}{c}\text { Standard } \\
\text { Error }\end{array}$ & $t$ & $p$ & LLCI & ULCI \\
\hline Constant & 3.7422 & 0.6238 & 5.9992 & 0.0000 & 2.5069 & 4.9776 \\
Fit $($ Fit $=1$, Misfit $=0$ ) & 0.0566 & 0.3886 & 0.1456 & 0.8845 & -0.7130 & 0.8261 \\
Focus (Prevention =1, Promotion $=0)$ & -0.3121 & 0.3921 & -0.7959 & 0.4277 & -1.0887 & 0.4645 \\
Fit x Focus & 1.3147 & 0.5556 & 2.3664 & 0.0196 & 0.2144 & 2.4150 \\
Gender (Male =1, Female =0) & 0.3138 & 0.2819 & 1.1133 & 0.2679 & -0.2444 & 0.8721 \\
Trait Vengeance & 0.6157 & 0.1931 & 3.1887 & 0.0018 & 0.2333 & 0.9981 \\
\hline
\end{tabular}

B. Dependent Variable: Intention to Disengage

\begin{tabular}{lcccccc} 
& Coefficient & $\begin{array}{c}\text { Standard } \\
\text { Error }\end{array}$ & $\mathrm{t}$ & $\mathrm{p}$ & LLCI & ULCI \\
\hline Constant & 3.9235 & 0.5136 & 7.6397 & 0.0000 & 2.9065 & 4.9405 \\
Fit $($ Fit = 1, Misfit =0) & 1.6645 & 0.2217 & 7.5094 & 0.0000 & 1.2256 & 2.1035 \\
Anger & 0.2347 & 0.0698 & 3.3625 & 0.0010 & 0.0965 & 0.3729 \\
Gender (Male =1, Female =0) & 0.3900 & 0.2202 & 1.7706 & 0.0792 & -0.0462 & 0.8261 \\
Trait Vengeance & 0.0445 & 0.1562 & 0.2845 & 0.7765 & -0.2649 & 0.3538 \\
\hline
\end{tabular}

C. Conditional Indirect Effect of Fit on Intention to Retaliate

\begin{tabular}{ccccc} 
Focus & Effect & Boot SE & Boot LLCI & Boot ULCI \\
\hline Promotion & 0.0133 & 0.1058 & -0.1855 & 0.2491 \\
Prevention & 0.3219 & 0.1518 & 0.0849 & 0.6729 \\
\hline
\end{tabular}

This author accepted manuscript is deposited under a Creative Commons Attribution Non-commercial 4.0 International (CC BY-NC) licence. This means that anyone may distribute, adapt, and build upon the work for non-commercial purposes, subject to full attribution. If you wish to use this manuscript for commercial purposes, please contact permissions@emerald.com. 